Tropical Journal of Pharmaceutical Research April 2019; 18 (4): 857-862

ISSN: $1596-5996$ (print); 1596-9827 (electronic)

(C) Pharmacotherapy Group, Faculty of Pharmacy, University of Benin, Benin City, 300001 Nigeria.

\title{
Effect of temozolomide combined with radiotherapy on survival and MGMT protein expression in recurrent malignant glioma patients
}

\author{
Feng Yun, Huang Honghui, Gao Jing, Liu Shizhu* \\ Medical College of Jiangsu University, Nanjing City, Jiangsu Province 212000, China
}

${ }^{*}$ For correspondence: Email: ds1293@163.com

Sent for review: 9 November 2018

Revised accepted: 27 March 2019

\begin{abstract}
Purpose: To investigate the effect of temozolomide (TMZ) combined with radiotherapy (RT) on O-6methylguanine-DNA methyltransferase (MGMT) protein and survival of recurrent malignant glioma patients.

Methods: Ninety-two patients with malignant glioma in our hospital from January 2014 to January 2015 were assigned to study and control groups using the random table method. Subjects in the control group received radiotherapy (total dose in the range of $60-75 \mathrm{~Gy}$ ), while those in the study group were given TMZ orally (75 mg/m2) daily in addition to radiotherapy, as well as TMZ at $150-200 \mathrm{mg} / \mathrm{m} 2$. After treatment, clinical effectiveness was compared for the two groups. Changes in methylation of MGMT gene were determined in the two groups. The patients were followed up for 3 years, and the degrees of survival and recurrence were recorded.

Results: Total effectiveness of clinical treatment was markedly higher in the study group (76.09\%) than in the control group (45.65\%; $p<0.05)$. One month after radiotherapy, significant decrease in MGMT gene methylation was seen in patients in the study group, relative to control patients $(p<0.05)$. Patients in the study group had lower median recurrence but higher degree of survival in the $2 n d$ and $3 r d$ years, relative to control patients $(p<0.05)$.

Conclusion: The combination of temozolomide and radiotherapy is more effective than radiotherapy in the treatment of recurrent malignant glioma. The combined treatment significantly inhibits tumor recurrence in patients, and improves their prognosis and standard of life.
\end{abstract}

Keywords: Temozolomide, Radiotherapy, Recurrent malignant glioma, Survival rate, MGMT protein

This is an Open Access article that uses a fund-ing model which does not charge readers or their institutions for access and distributed under the terms of the Creative Commons Attribution License (http://creativecommons.org/licenses/by/4.0) and the Budapest Open Access Initiative (http://www.budapestopenaccessinitiative.org/read), which permit unrestricted use, distribution, and reproduction in any medium, provided the original work is properly credited.

Tropical Journal of Pharmaceutical Research is indexed by Science Citation Index (SciSearch), Scopus, International Pharmaceutical Abstract, Chemical Abstracts, Embase, Index Copernicus, EBSCO, African Index Medicus, JournalSeek, Journal Citation Reports/Science Edition, Directory of Open Access Journals (DOAJ), African Journal Online, Bioline International, Open-J-Gate and Pharmacy Abstracts

\section{INTRODUCTION}

Gliomas are tumors derived from neuro-epithelial tissue, and the most common primary intracranial tumors. The World Health Organization (WHO) classified gliomas into grades (1 -IV). Grades III and IV are malignant gliomas which account for
$40-50 \%$ of all gliomas [1, 2]. Malignant glioma is invasive. Thus, it has no obvious boundary with normal brain tissue, and it easily relapses after surgical resection. Therefore, it is usually treated with a combination of radiotherapy and chemotherapy. Traditional alkylating agents and chemotherapeutic drugs are the first choices for 
clinical treatment, but most of these drugs cannot penetrate the blood-brain barrier. In addition, they have lots of side effects, and their effectiveness is poor [3]. Studies have shown that $\mathrm{TMZ}$, a new anti-tumor activity and alkylating agent, can get through the blood-brain barrier, is highly effective, and is associated with very few adverse reactions [4]. In this study, TMZ was combined with radiotherapy and used to treat recurrent malignant glioma. The degree of survival, and the impact of the combined therapy on MGMT protein were determined.

\section{METHODS}

\section{General clinical information on patients}

Ninety-two malignant glioma patients were used as subjects in this study.

Inclusion criteria: Patients in the following categories were included: patients with malignant glioma recurrence confirmed by biopsy or postoperative pathology; glioma patients in grade III or grade IV consistent with WHO central nervous system tumor grade; glioma patients aged 18 years or above, with estimated survival time $\geq 3$ months; patients with Cartesian function score > 60 points; glioma patients who had not received other radiotherapy and chemotherapy within the month preceding the study, and patients who signed informed consent with their family members for the treatment.

Exclusion criteria: Patients with a history of other malignant tumors, glioma patients with heart, hepatic and renal dysfunctions, and cardiovascular and hematopoietic diseases; and patients with contraindications for radiotherapy and chemotherapy, were excluded. Other excluded patients included those with severe allergies, especially those who are allergic to $\mathrm{TMZ}$; pregnant and lactating patients, patients who did not follow doctor's advice on the treatment regimen, and those who refused to be followed up. The patients comprised 52 men and 40 women in the age range of 20 - 76 years (mean age $=51.9 \pm 3.5$ years). There were 50 cases of grade III glioma, and 42 cases of grade IV glioma. Two equal groups of patients were used: observation and control groups (46 patients /group). The observation and control groups had no appreciable differences in age, gender and pathological grade $(p>0.05)$. The general clinical data of the patients are shown in Table 1.

This research received approval from the Ethical Committee of Affiliated Hospital of Medical College of Jiangsu University (approval no.
20187879), and was performed according to the guidelines of Declaration of Helsinki promulgated in 1964 as amended in 1996 [5].

Table 1: Baseline profile of the patients

\begin{tabular}{lccc}
\hline Variable & $\begin{array}{c}\text { Study } \\
\text { group }\end{array}$ & $\begin{array}{c}\text { Control } \\
\text { group }\end{array}$ & $\boldsymbol{P}$ value \\
\hline Sex: Male/Female & $27 / 19$ & $25 / 21$ & 0.547 \\
Mean age (years) & $52.4 \pm$ & $51.3 \pm$ & 0.982 \\
& 3.1 & 3.5 & \\
KPS score & $69.3 \pm$ & $68.5 \pm$ & 0.701 \\
Pathological grade & 12.1 & 12.8 & \\
III & 26 & 24 & 0.679 \\
IV & 24 & 18 & \\
Surgical resection & 6 & 10 & 0.897 \\
under microscope & & & \\
Most/near full & 30 & 25 & \\
resection & 10 & 14 & \\
$\begin{array}{l}\text { Biopsy only/not } \\
\text { removed }\end{array}$ & & & \\
\hline
\end{tabular}

\section{Treatment}

All patients received chemo-radiotherapy 2 to 4 weeks after surgery. The subjects in the control group received radiotherapy alone. Using CTsimulated three-dimensional conformal radiotherapy (3D-CRT) technique, each of the patients was placed in the supine position for CT and MRI positioning, and the head was fixed with skull fixing plate. The $3 \mathrm{~mm}$ thin layer continuous enhanced CT was coplanar or non-coplanar irradiation, and the clinical target area included the surgical margin as tumor target or the area 2 - $3 \mathrm{~cm}$ outside the edema. The planned target area was $0.5-1.0 \mathrm{~cm}$ outside the clinical target area. The target area specification was delineated, and the radiotherapy dose was 2 Gy/time/day after conventional segmentation, and 5 times a week. The total dose was $60 \mathrm{~Gy}$. The study group received oral TMZ $\left(75 \mathrm{mg} / \mathrm{m}^{2}\right)$ along with radiotherapy, with continuous administration for 5 days, and discontinuation for 23 days (one treatment cycle was 28 days). Thereafter, TMZ $\left(150-200 \mathrm{mg} / \mathrm{m}^{2}\right)$ was given as adjuvant chemotherapy once and 5 days before each radiotherapy. According to the patient's reaction, mannitol and dexamethasone were given to reduce cerebral edema reaction.

\section{Study indicators}

\section{Clinical efficacy}

Clinical effectiveness (TE) was assessed using the following criteria according to the $\mathrm{WHO}$ effectiveness evaluation criteria [6]: (a) Complete remission (CR): complete disappearance of tumor sustained for at least 4 weeks; (b) Partial remission $(P R)$ : reduction in tumor lesion volume 
by more than $50 \%$, at least for 4 weeks; (c) Stable (SD) : tumor lesion volume reduction $<50$ $\%$ or tumor volume increase not exceeding $25 \%$ for at least 4 weeks; (d) Progression (PD): $25 \%$ increase in at least one lesion.

$T E=\frac{(C R+P R)}{\mathrm{N}} \times 100$

where TE is total effectiveness and $\mathrm{N}$ is total number of cases.

\section{Quality of life}

This was based on the pre-treatment Kelvin score (KPS). An increase of 10 points in the patient's KPS score indicated improvement in the quality of life, and a reduction by 10 points indicated reduced quality of life. An increase less than 10 points or the decrease not more than 10 indicated stable quality of life.

\section{Plasma MGMT protein}

The degree of methylation of MGMT gene was assessed using nested methylation-specific PCR.

\section{Long-term efficacy}

The extent of survival of patients and the degree of recurrence in the first, second and third years were determined through regular follow-up of patients after treatment.

\section{Adverse reactions}

Routine blood tests and liver and kidney function tests were performed weekly during treatment to evaluate the adverse drug reactions and drug resistance.

Table 2: Clinical efficacy of treatments $\{n(\%)\}$

\section{Statistical analysis}

Numeric data are presented as mean \pm SD, and were statistically analyzed with $t$-test. Count data are expressed as $n(\%)$, and $x^{2}$ test was used for analysis. Statistical Package for the Social Sciences, version 19, was used for statistical analyses. Statistical significance was fixed at $p<$ 0.05 .

\section{RESULTS}

\section{Clinical effects post-treatment}

Table 2 shows that after treatment, the study group had higher total effectiveness (76.09\%) than control group (45.65 \%, $p<0.05)$.

\section{Quality of life scores}

As shown in Table 3, after treatment, KPS score was higher in the observation group (80.16 \pm 4.52 than the corresponding control value (71.56 $\pm 2.35 ; p<0.05)$. Improvement in quality of life in the observation patients was markedly higher than that in control patients $(p<0.05)$.

\section{Differences in positive methylation of MGMT genes}

As shown in Table 4, before radiotherapy, MGMT methylation in both groups were comparable $(p>$ 0.05). However, one month after the start of radiotherapy, higher degree of MGMT gene methylation was seen in the control group patients $(30.43 \%)$ than in the observation group patients $(13.04 \%)(p<0.05)$. After the treatment, MGMT gene methylation in both groups were comparable $(p>0.05)$.

\begin{tabular}{llllll}
\hline Group & CR & PR & SD & PD & ORR \\
\hline Study (46) & $12 \mathrm{n} 26.09)$ & $23(50.00)$ & $6(13.04)$ & $5(10.87)$ & $35(76.09)$ \\
Control (46) & $9(19.57)$ & $12(26.09)$ & $11(23.91)$ & $14(30.43)$ & $21(45.65)$ \\
$X^{2}$ & 2.674 & 4.592 & -2.154 & -3.027 & 6.813 \\
$p$ & 0.032 & 0.013 & 0.037 & 0.029 & 0.004 \\
\hline $\mathrm{n}=46$ & & & & &
\end{tabular}

Table 3: Quality of life improvement $\{n(\%)\}$

\begin{tabular}{llll}
\hline Group & Improvement in quality of life & Reduced quality of life & Stable quality of life \\
\hline Study & $26(56.52)$ & $9(19.57)$ & $11(23.91)$ \\
Control & $19(41.30)$ & $15(32.61)$ & $12(26.09)$ \\
$X^{2}$ & 2.674 & -2.154 & 4.592 \\
$p$ & 0.032 & 0.037 & 0.013 \\
\hline
\end{tabular}


Table 4: Methylation of MGMT genes $\{n(\%)\}$

\begin{tabular}{lccc}
\hline Group & \multicolumn{3}{c}{$\begin{array}{c}\text { Methylation } \\
\text { cases }\{\mathrm{n}(\%)\}\end{array}$} \\
\cline { 2 - 4 } & $\begin{array}{c}\text { Before } \\
\text { treatment }\end{array}$ & $\begin{array}{c}\text { 1 month after } \\
\text { treatment }\end{array}$ & $\begin{array}{c}\text { 3 years } \\
\text { after } \\
\text { treatment }\end{array}$ \\
\hline Study & $17(36.95)$ & $6(13.04)$ & $3(6.52)$ \\
Control & $16(34.78)$ & $14(30.43)$ & $8(17.39)$ \\
$X^{2}$ & 0.043 & 4.574 & 2.210 \\
$p$ & 0.836 & 0.032 & 0.137 \\
\hline
\end{tabular}

\section{Survival rate and recurrence}

Table 5 shows that the percentage survival values in the two groups in the first year were comparable $(p>0.05)$. However, in year two and year three, higher percentage survival and median time of recurrence were seen in the observation group patients, relative to control patients $(p<0.05)$.

\section{Adverse reactions}

As shown in Table 6, the side effects seen in the two groups were myelosuppression, nausea and vomiting; and fever and anemia, mostly in $1^{\text {st }}$ and $2^{\text {nd }}$ degrees. There were no significant differences in adverse reactions between the two groups $(p>0.05)$.

\section{DISCUSSION}

Gliomas are common central nervous system tumors. Patients with gliomas often have high intracranial pressure symptoms, and some patients have seizures. Generally, it is thought that the symptoms are related to genetic, environmental, immune dysfunction and other factors [7]. Studies have shown that residual tumor cells are the main cause of recurrence of malignant gliomas. Once malignant gliomas recur, the growth rate is very rapid, and it is very invasive [8,9]. Therefore, postoperative adjuvant radiotherapy and chemotherapy are the main treatment options against malignant glioma.

However, traditional chemotherapeutic drugs have limited effectiveness because they bind to plasma proteins, and so cannot pass the bloodbrain barrier. They also inhibit hematopoietic function of the bone marrow. Temozolomide (TMZ), a highly effective and low-toxicity imidazole derivative, is rapidly absorbed orally and can directly penetrate the blood-brain barrier and enter the cerebrospinal fluid to act on brain tumor tissues. It is very effective against primary and recurrent malignant gliomas [10].

Studies have shown that TMZ has a synergistic effect when combined with radiotherapy for treatment of malignant glioma: the combined treatment significantly improves long-term survival, and exerts mild adverse reactions [11]. This study found that the combination of TMZ and radiotherapy was significantly more effective in treating malignant glioma patients than radiotherapy alone. Total efficacy in the study group was $76.09 \%$, which was markedly superior to that in control group (45.65\%). Moreover, improvement in quality of life was appreciably higher in the study group than in the control. These findings suggest that $T M Z$ combined with radiotherapy is clinically effective in patients with malignant glioma and improves their quality of life. These results are consistent with the reports of Zhang and Cui [12].

The main adverse reaction of $T M Z$ is myelosuppression. In this study, there were 9 cases of myelosuppression in the observation group, accounting for $19.57 \%$, and 8 cases in the control group, accounting for $17.39 \%$.

Table 5: Survival rate and recurrence time for patients $\{n(\%\}]$

\begin{tabular}{lllll}
\hline Group & \multicolumn{1}{|c}{$\begin{array}{c}\mathbf{1}^{\text {st }} \text { year survival }\{\mathbf{n} \\
(\%)\}\end{array}$} & $\begin{array}{c}\mathbf{2}^{\text {nd }} \text { year survival }\{\mathbf{n} \\
(\%)\}\end{array}$ & $\begin{array}{c}\mathbf{3}^{\text {rd }} \text { year survival }\{\mathbf{n} \\
(\%)\}\end{array}$ & $\begin{array}{c}\text { Median recurrence } \\
\text { time }(\mathbf{m o n t h s})\end{array}$ \\
\hline Study & $40(86.95)$ & $30(65.22)$ & $17(39.53)$ & $21.65 \pm 9.32$ \\
Control & $33(71.73)$ & $15(32.61)$ & $7(15.22)$ & $14.36 \pm 8.56$ \\
$P$-value & $>0.05$ & $<0.05$ & $<0.05$ & $<0.05$ \\
\hline
\end{tabular}

Table 6: Incidence of adverse reactions $\{\mathrm{n}(\%)\}$

\begin{tabular}{lcccc}
\hline Adverse reaction & $\begin{array}{c}\text { Study group } \\
(\mathbf{n = 4 6 )}\end{array}$ & $\begin{array}{c}\text { Control group } \\
(\mathbf{n = 4 6 )}\end{array}$ & $\mathbf{X}^{\mathbf{2}}$ & $\boldsymbol{P}_{\text {-value }}$ \\
\hline Reduced white blood cell count & $8(17.39)$ & $5(10.86)$ & 1.013 & 0.092 \\
Radioactive brain edema & $7(15.21)$ & $5(10.86)$ & 0.692 & 0.346 \\
Nausea/vomiting & $8(17.39)$ & $7(15.21)$ & 0.958 & 0.087 \\
Fever & $3(6.52)$ & $2(4.34)$ & 0.263 & 0.739 \\
Myelosuppression & $9(19.57)$ & $8(17.39)$ & 1.171 & 0.068 \\
Anemia & $7(15.21)$ & $5(1086)$ & 0.703 & 0.294 \\
\hline
\end{tabular}


This study has revealed that TMZ combined with radiotherapy for treating malignant glioma has high safety and low adverse reactions, and bone marrow suppression did not accumulate. In a 3year follow-up of the patients, first-year survival in the two groups were comparable, but the second and third-year survival and median recurrence times were markedly higher in the observation group. These findings confirm that TMZ combined with radiotherapy is effective in inhibiting tumor cells, reducing recurrence and prolonging survival of patients. This is in agreement with previous reports [13].

Studies have shown that MGMT expression is implicated in resistance to $T M Z$ in malignant glioma. The MGMT gene is a DNA repair gene which is important for tumor repair, and can transfer alkyl groups from guanine to itself. On the cysteine residue, the alkylating agent guanine on the DNA is reduced, and MGMT becomes the inactive alkylating group. This eliminates the toxic effect of the alkylating agent on the tumor cells, resulting in resistance to TMZ [14]. Therefore, before the treatment of malignant glioma, the positive expression of MGMT protein in the tumor tissue is determined, and different chemotherapy regimens are then formulated according to the sensitivity of the tumor to the alkylating agent.

This study showed that the positive methylation of MGMT in both groups were comparable prior to treatment. However, one month after the start of radiotherapy, the methylation of MGMT gene in study group was markedly decreased (13.04 $\%)$, relative to corresponding control value (30.43 $\%)$. This reflects the re-inhibition of tumor proliferation by chemotherapy. The reason is that TMZ is rapidly converted to methyltriazepenimidamide under the certain hydrogen ion concentration in the stage of tumor cell division. It exerts its cytotoxic effect by enhancing DNA alkylation in tumor cells. Temozolomide increases sensitivity to radiotherapy and promotes its anti-carcinogenic properties $[15,16]$.

\section{Limitations of the study}

Few participants took part in this study. The subjects were all from Asia i.e. only from one area. So, the application of the conclusion drawn from this work is limited.

\section{CONCLUSION}

The combination of TMZ and radiotherapy is clinically effective, and significantly improves the quality of life of malignant glioma patients by reducing the positive expression of plasma
MGMT protein. It inhibits tumor proliferation and recurrence, prolongs survival time of patients, and is associated with reduced adverse reactions. Thus, the combination treatment appears safe and easily tolerated by patients.

\section{DECLARATIONS}

\section{Acknowledgement}

This work was supported by The 2nd Ministry of Education in 2016 to study in China Pharmacology; English Courses for Foreign Students of Jiangsu Province in Jiangsu Province in 2015 Pharmacology; Key Projects of the 2015 Higher Education Teaching Reform Research Project of Jiangsu University (no. 2015JGZD027); 2012 Jiangsu Postdoctoral Fund (no. 1202041C).

\section{Conflict of interest}

No conflict of interest is associated with this work.

\section{Contribution of authors}

We declare that this work was done by the author(s) named in this article and all liabilities pertaining to claims relating to the content of this article will be borne by the authors. All authors read and approved the manuscript for publication. Liu SZ conceived and designed the study. Feng Yun, Huang Honghui, Gao Jing and Liu SZ collected and analyzed the data, while Feng Yun wrote the manuscript.

\section{Open Access}

This is an Open Access article that uses a funding model which does not charge readers or their institutions for access and distributed under the terms of the Creative Commons Attribution License (http://creativecommons.org/licenses/by/ 4.0) and the Budapest Open Access Initiative (http://www.budapestopenaccessinitiative.org/rea d), which permit unrestricted use, distribution, and reproduction in any medium, provided the original work is properly credited.

\section{REFERENCES}

1. Park DY, Lauwers GY. Gastric polyps: classification and management. Arch Pathol Lab Med 2008; 132: 633-640.

2. Kim YH, Kim NG, Lim JG, Park C, Kim H. Chromosomal Alterations in Paired Gastric Adenomas and Carcinomas. Am J Pathol 2001; 158: 655-662. 
3. Carmack SW, Genta RM, Schuler CM, Saboorian MH. The current spectrum of gastric polyps: a 1-year national study of over 120,000 patients. Am J Gastroenterol 2009; 104: 1524-1532.

4. Goddard AF, Badreldin R, Pritchard DM, Walker MM, Warren $B$. The management of gastric polyps. Gut 2010; 59: 1270-1276.

5. Qin F, Huang $X$, Ren $P$. Chinese herbal medicine modified xiaoyao san for functional dyspepsia: Meta-analysis of randomized controlled trials. J Gastroenterol Hepatol 2009; 24: 1320-1325.

6. Xiao Y, Liu Yy, Yu Kq, Ouyang Mz, Luo R, Zhao Xs. Chinese herbal medicine liu jun zi tang and xiang sha liu jun zi tang for functional dyspepsia: meta-analysis of randomized controlled trials. Evid Based Complement Alternat Med 2012; 2012.

7. Singhuber J, Zhu M, Prinz S, Kopp B. Aconitum in traditional Chinese medicine: $A$ valuable drug or an unpredictable risk? J Ethnopharmacol 2009; 126: 18-30.

8. Gu Y, Zhang Y, Shi X, Li X, Hong J, Chen J, Gu W, Lu X, $X u G$, Ning $G$. Effect of traditional Chinese medicine berberine on type 2 diabetes based on comprehensive metabonomics. Talanta 2010; 81: 766-772.

9. Tian L. Shen-ling-bai-zhu decoction scattered flavored rhubarb protect the intestinal mucosal barrier function of experimental research. Med J Liaoning 2011; 01: 9-11.

10. Xi S, Peng Y, Minuk GY, Shi M, Fu B, Yang J, Li Q, Gong $Y$, Yue $L, L i L$ et al. The combination effects of ShenLing-Bai-Zhu on promoting apoptosis of transplanted H22 hepatocellular carcinoma in mice receiving chemotherapy. J Ethnopharmacol 2016; 190: 1-12.

11. Jia Taiyuan BHS. Dangshen for $\mathbf{J 7 7 4}$ rat effect of the activity of macrophage cell. Lishizhen Med Mater Med Res 2010; 11: 769-770.

12. Wangruina. The pharmacological effects and the comprehensive development and utilization of medicinal atractylodes. Anhui Ag Sci 2010; 38: 5610-5611, 5627.

13. Wu Y, Yuan Y. Advance in studies on chemical components and pharmacological effect of Semen Coicis. West Pharm J 2010; 25: 111-113.

14. Lu J, Cai J, Dai Y. Research progress of Semen Dolichoris Album. Hubei J TCM 2013; 35: 77-79. 